\title{
Quality of life of Australian chronically-ill adults: patient and practice characteristics matter
}

\author{
Upali W Jayasinghe*1, Judith Proudfoot ${ }^{1}$, Christopher A Barton ${ }^{2}$, \\ Cheryl Amoroso ${ }^{1}$, Chris Holton ${ }^{2}$, Gawaine Powell Davies ${ }^{1}$, Justin Beilby ${ }^{3}$ and \\ Mark F Harris ${ }^{1}$
}

Address: ${ }^{1}$ Centre for Primary Health Care and Equity, School of Public Health \& Community Medicine, University of New South Wales, Sydney, New South Wales, Australia, ${ }^{2}$ Discipline of General Practice, University of Adelaide, Adelaide, South Australia, Australia and ${ }^{3}$ Faculty of Health Sciences, University of Adelaide, Adelaide, South Australia, Australia

Email: Upali W Jayasinghe* - upali.jay@unsw.edu.au; Judith Proudfoot - j.proudfoot@unsw.edu.au; Christopher A Barton - christopher.barton@adelaide.edu.au; Cheryl Amoroso - cheryl.amoroso@yahoo.com; Chris Holton - christine.holton@adelaide.edu.au; Gawaine Powell Davies - g.powell-davies@unsw.edu.au; Justin Beilby - justin.beilby@adelaide.edu.au; Mark F Harris - m.f.harris@unsw.edu.au

* Corresponding author

Published: 3 June 2009

Health and Quality of Life Outcomes 2009, 7:50 doi:10.1 I86/1477-7525-7-50
Received: 15 January 2009

Accepted: 3 June 2009

This article is available from: http://www.hqlo.com/content/7/1/50

(C) 2009 Jayasinghe et al; licensee BioMed Central Ltd.

This is an Open Access article distributed under the terms of the Creative Commons Attribution License (http://creativecommons.org/licenses/by/2.0), which permits unrestricted use, distribution, and reproduction in any medium, provided the original work is properly cited.

\begin{abstract}
Background: To study health-related quality of life (HRQOL) in a large sample of Australian chronically-ill patients and investigate the impact of characteristics of patients and their general practices on their HRQOL and to assess the construct validity of SF- 12 in Australia.
\end{abstract}

Methods: Cross sectional study with 96 general practices and 7606 chronically-ill patients aged 18 years or more using standard SF- 12 version 2. Factor analysis was used to confirm the hypothesized component structure of the SF-I2 items. SF-12 physical component score (PCS-I2) and mental component score (MCS-12) were derived using the standard US algorithm. Multilevel regression analysis (patients at level I and practices at level 2) was applied to relate PCS- 12 and MCS- 12 to patient and practice characteristics.

Results: There were significant associations between lower PCS- 12 or MCS- 12 score and poorer general health (10.8 (regression coefficient) lower for PCS-12 and 7.3 lower for MCS-12), low socio-economic status (5.1 lower PCS- 12 and 2.9 lower MCS- 12 for unemployed, 0.8 lower PCS12 and 1.7 lower MCS- 12 for non-owner-occupiers, 1.0 lower PCS- 12 for less well-educated) and having two or more chronic conditions (up to 2.7 lower PCS- 12 and up to 1.5 lower MCS- 12 than those having a single disease). Younger age was associated with lower MCS-12 (2.2 and 6.0 lower than middle age and older age respectively) but higher PCS-12 (4.7 and 7.6 higher than middle age and older age respectively). Satisfaction with quality of care (regression coefficient $=1.2$ ) and patients who were married or cohabiting (regression coefficient $=0.6$ ) was positively associated with MCS-12. Patients born in non-English-speaking countries were more likely to have a lower MCS- 12 (1.5 lower) than those born in Australia. Employment had a stronger association with the quality of life of males than that of females. Those attending smaller practices had lower PCS- 12 (I.0 lower) and MCS- 12 ( 0.6 lower) than those attending larger practices. At the patient level (level I) $42 \%$ and $21 \%$ of the variance respectively for PCS- 12 and MCS- 12 were explained by the patients 
and practice characteristics. At the practice level (level 2), $73 \%$ and $49 \%$ of the variance respectively for PCS- 12 and MCS- 12 were explained by patients and practice characteristics.

Conclusion: The strong association between patient characteristics such as socio-economic status, age, and ethnicity and SF-I 2 physical and mental component summary scores underlines the importance of considering these factors in the management of chronically-ill patients in general practice. The SF- 12 appears to be a valid measure for assessing HRQOL of Australian chronicallyill patients.

\section{Background}

In 2004, 77\% of Australians reported having at least one long term medical condition [1]. Patients with chronic conditions account for an increasing burden of disease and presentations in general practice in Australia [2,3] and the proportion of encounters for both diabetes and cardiovascular disorders is increasing [3]. The management of chronic illness has thus become a major focus in general practice, both because of its prevalence and the opportunity which general practice has to intervene early to improve quality of life, prevent disability and reduce hospital use. Since 1999, the Australian government has introduced a variety of strategies to improve the care of people with chronic illness [4]. Having effective ways of assessing the health status of patients is critical to the evaluation and monitoring of these strategies [5].

The measurement of health-related quality of life (HRQOL) from the perspective of the patient has become a major aspect of health services evaluation [6]. The standardized measurement of health outcomes, through instruments such as the SF-36, and more recently the SF-12, has had significant benefit for all fields and professions concerned with health $[7,8]$. In particular, standardized assessment of health status is valuable for assessing the effectiveness of medical interventions, for monitoring the progress of patients in clinical settings, and for evaluating health and well-being at the population level [9]. Investigators from numerous countries representing diverse cultures have determined that the SF-36 and SF-12 are sensitive to differences in a number of socio-demographic and clinical variables, including age $[8,10]$, gender $[8,11]$, income [7,11-13], employment $[7,11,14]$, education $[7,9,12,14]$, self reported general health [10], marital status [15], ethnicity [6,9] and number of conditions $[10,12]$.

The study aimed to examine variations in the two subscales of the SF-12 ('physical component score (PCS-12)' and 'mental component score (MCS-12)') according to practice and patient characteristics as well as satisfaction with care and the number of medical conditions in a pop- ulation of chronically-ill patients attending Australian general practice. It also examined the construct validity of SF-12 in this population.

\section{Methods \\ Participants}

This study was part of a larger study examining the impact of the organizational capacity of general practices in Australia to manage chronic diseases. It was conducted in 27 Divisions (local primary care support organizations) in five states and in the Australian Capital Territory between December 2003 and October 2004. The data on Division characteristics showed that the 27 were representative of the 103 Divisions approached except that recruited general practices from 27 Divisions tended to be larger and to have a lower population to general practitioners ratio than the Australian average [16]. In each practice, clinical management software was used to select a random sample of 180 patients aged 18 years or more currently being prescribed medication for three common chronic diseases: asthma, type 2 diabetes, and hypertension/ischaemic heart disease. Practices were permitted to remove patients from the list who were deceased or otherwise inappropriate to invite. A total of 12,544 patients attending 96 practices were invited to participate. Completed surveys were received from 7606 patients (a response rate of 61\%). A priori sample size calculations on the SF-12 physical component score confirmed that after adjustment for clustering (previous studies on SF-36 indicated a cluster effect (ICC = Intra-cluster correlation) of 0.011 for the PCS-36 [14]) predicted that an average of 50 patients from each of 100 practices would have sufficient power $(1-\beta=0.8$ and $\alpha=0.05$ ) to detect an effect size of 0.10 between patients with good and poor general health assuming that about half of the patients were in good general health.

\section{Ethics}

Ethics approval for the study was obtained from the University of New South Wales (UNSW) Human Research Ethics Committee and University of Adelaide Human Research Ethics Committee. Both practice staff and patients provided written informed consent. 


\section{Instruments}

The standard SF-12 version 2 is a 12-item questionnaire measuring physical and mental health $[6,12]$. The adoption of the SF-12 version 2 over the original version 1 form for all new studies including population surveys is recommended [17]. It is an abbreviated form of the SF-36 Health Survey, which is one of the most widely used instruments for assessing HRQOL [12]. Both instruments produce eight dimensions of health (physical functioning $(\mathrm{PF})$, role physical $(\mathrm{RF})$, bodily pain $(\mathrm{BP})$, general health $(\mathrm{GH})$, vitality $(\mathrm{VT})$, social functioning $(\mathrm{SF})$, role emotional (RE), and mental health $(\mathrm{MH}))[18,19]$. They also produce two summary scores - the Physical Component Summary (PCS) and the Mental Health Component Summary (MCS) - and have been validated for use in the USA, UK and many other European countries for large scale health measurement and monitoring [12,19]. For ease of interpretation, scores are standardized to population norms, with the mean score set at 50 ( $\mathrm{SD}=10)$ : higher scores indicate better health. The SF-12 has been shown to have good validity and reliability [17]. Previous research has supported the use of the standard SF-12 in Australian settings, rather than development of an 'Australian' shortform [20,21]. The SF-12 is an instrument that can be administered in three minutes with a small trade off between brevity and precision [21].

The same sample of patients completed the General Practice Assessment Survey (GPAS) version 2 [22] along with the SF-12. The patient characteristics including selfreported general health and chronic medical condition/ conditions were collected using the GPAS. Patient satisfaction was also assessed through the GPAS. The GPAS is a multi-item self-report questionnaire which measures several dimensions relating to patients' assessment of general practice. The psychometric properties of the GPAS have been evaluated [23].

\section{Data and variables}

The dependent variables were PCS-12 and MCS-12. Because patients do not register with general practitioners (GPs) in Australia, it was not possible to determine the "list size" of practices accurately and thus the number of general practitioners in a practice was used as a measure of the practice size. Geographical area was defined by using the Rural, Remote and Metropolitan Area (RRMA) classification [24] as urban (all metropolitan centers with populations $\geq 100,000$ ) or rural (rural centers and all other areas with populations of less than 100,000). There were no practices in the sample which were zoned as remote. The socio-demographic characteristics of respondents studied were gender, age, self-reported general health status in the last 12 months, home ownership, education, employment, marital status, country of birth, disease and overall satisfaction with care (Table 1). Home ownership can be considered as one marker of economic status [25]. For some respondents, their specific chronic disease or diseases were not known and therefore 'unknowns' were included in the analysis as a separate category to minimize the data loss.

\section{Statistical analyses}

Summary physical (PCS-12) and mental (MCS-12) components were constructed using the standard SF-12 version 2 US algorithm empirically derived from the data of a US general population survey [17]. To confirm the dimensions as documented by Kontodimopoulos et al. [26] and Ware et al. [17], we carried out a factor analysis using SPSS statistical software (version 15; SPSS, Chicago, IL, USA) with principal components analysis using the varimax rotation [26]. The number of factors was determined by the scree test and eigen values $>1$. The two principal components were then rotated into simple orthogonal structures, a procedure previously implemented in similar studies [26]. It was hypothesized that two factors would be obtained (Table 2) known as physical health and mental health. In addition, items originally belonging to the PF, RP, BP and GH domains were hypothesized to load (or correlate) higher on the physical health factor, whereas the MH, RE, SF and VT items were hypothesized to relate most strongly to the mental health factor. However, VT and SF have been shown to load on both physical and mental components [26].

First, we examined the association between the independent variables and physical or mental health component scores in univariate analyses with analysis of variance using SPSS (Table 1). The analysis of variance was conducted to compare unadjusted scores. The Pearson $\chi^{2}-$ test was used to compare proportions analyzed and missing.

\section{Multilevel Models}

Multilevel regression models were used with two dimensions (physical and mental component scores) as continuous dependent variables and general practice and patient characteristics, including the hypothesized interaction between gender and employment (based on the previous studies $[15,27,28])$, as the independent variables. Multilevel analysis (with MLwiN Software [29]) adjusted for clustering of patients (level 1) within practices (level 2) $[11,14,30]$. Initially, we fitted a baseline variance component model (no independent variables) for each of the response variables followed by the main model. The main model expands the baseline model by including patient and practice characteristics with the hypothesized interaction $[15,27,28]$ as fixed effects. The interaction effect of independent variables was included in the model if their 
Table I: Unadjusted mean and standard deviation of PCS- 12 and MCS- 12 scores by characteristics of practices and patients (number of patients $=7606$; number of practices $=96$ )

\begin{tabular}{|c|c|c|c|c|c|c|}
\hline \multirow[t]{2}{*}{ Variable (definition) } & \multicolumn{2}{|c|}{ Responses } & \multicolumn{2}{|c|}{ PCS-12 } & \multicolumn{2}{|c|}{ MCS-12 } \\
\hline & No. & $\%$ & $\begin{array}{l}\text { Mean } \\
\text { (SD) }\end{array}$ & P-value & $\begin{array}{l}\text { Mean } \\
(\mathrm{SD})\end{array}$ & P-value \\
\hline \multicolumn{7}{|l|}{ Characteristics of practices } \\
\hline I-3 general practitioners & 3970 & 52.2 & $41.8(11.7)$ & $<0.001$ & $48.8(1 \mathrm{I} .4)$ & 0.016 \\
\hline 4 or more general practitioners & 3636 & 47.8 & $43.0(11.9)$ & & $49.4(10.8)$ & \\
\hline \multicolumn{7}{|l|}{ Location of practice: } \\
\hline Urban & 4468 & 60.1 & $42.8(11.8)$ & 0.001 & $49.0(11.0)$ & 0.698 \\
\hline Rural & 3038 & 39.9 & $41.8(11.9)$ & & $49.2(11.2)$ & \\
\hline \multicolumn{7}{|l|}{ Characteristics of patients } \\
\hline \multicolumn{7}{|l|}{ Gender: } \\
\hline Male & 3474 & 46.8 & $42.7(11.6)$ & 0.16 & $49.8(10.9)$ & $<0.001$ \\
\hline Female & 3944 & 53.2 & $42.3(12.0)$ & & $48.5(11.3)$ & \\
\hline \multicolumn{7}{|l|}{ Age (years): } \\
\hline $18-39$ Yrs & 749 & 10.1 & $50.4(9.3)$ & $<0.001$ & $45.0(11.7)$ & $<0.001$ \\
\hline $40-59$ Yrs & 2538 & 34.3 & $44.7(11.4)$ & & $47.3(11.3)$ & \\
\hline$>59$ yrs & 4115 & 55.6 & $39.5(11.5)$ & & $51.0(10.5)$ & \\
\hline \multicolumn{7}{|l|}{ Health status } \\
\hline Good & 4027 & 54.4 & $48.2(8.9)$ & $<0.001$ & $52.8(8.9)$ & $<0.001$ \\
\hline Poor & 3382 & 45.6 & 35.5 (II.2) & & 44.6 (II.9) & \\
\hline \multicolumn{7}{|l|}{ Home ownership } \\
\hline Owner-occupied & 5899 & 79.8 & $43.0(11.7)$ & $<0.001$ & $49.9(10.7)$ & $<0.001$ \\
\hline Rented & 1496 & 20.2 & $40.4(12.2)$ & & $46.0(12.1)$ & \\
\hline \multicolumn{7}{|l|}{ Education } \\
\hline Degree/Diploma & 2208 & 30.1 & $45.8(11.2)$ & $<0.001$ & $48.7(11.1)$ & 0.071 \\
\hline Elementary/High School & 5138 & 69.9 & $41.0(11.8)$ & & $49.3(11.1)$ & \\
\hline \multicolumn{7}{|l|}{ Employment } \\
\hline Employed & 2536 & 34.3 & $48.4(9.2)$ & $<0.001$ & $49.3(10.2)$ & $<0.001$ \\
\hline Retired & 2935 & 39.7 & $39.9(11.3)$ & & $51.4(10.3)$ & \\
\hline $\begin{array}{l}\text { Unemployed } \\
\text { (looking for work/full-time education/looking after family/unable to work due to } \\
\text { sickness or disability) }\end{array}$ & 1923 & 26.0 & $38.3(12.5)$ & & $45.3(12.4)$ & \\
\hline \multicolumn{7}{|l|}{ Marital status } \\
\hline Married (married/cohabiting) & 5206 & 70.3 & $43.1(11.6)$ & $<0.001$ & $49.7(10.8)$ & $<0.001$ \\
\hline Unmarried (single/separated/divorced/widowed) & 2200 & 29.7 & $41.0(12.3)$ & & $47.6(11.8)$ & \\
\hline \multicolumn{7}{|l|}{ Country of birth } \\
\hline Born in Australia & 5474 & 74.6 & $42.6(11.8)$ & 0.008 & $49.2(11.0)$ & 0.001 \\
\hline Born in USA/UK/Canada/New Zealand & 1001 & 13.7 & $42.8(12.0)$ & & $49.6(11.2)$ & \\
\hline Born in non-English-speaking countries & 858 & 11.7 & $41.3(11.4)$ & & $47.8(11.7)$ & \\
\hline \multicolumn{7}{|l|}{ Disease } \\
\hline Diabetes & 1043 & 13.7 & $42.7(10.9)$ & $<0.001$ & $50.2(10.4)$ & $<0.001$ \\
\hline Ischaemic heart disease/hypertension & 1404 & 18.5 & 40.5 (II.5) & & $49.3(10.7)$ & \\
\hline Asthma & 792 & 10.4 & $42.8(11.7)$ & & $47.7(11.0)$ & \\
\hline Two or more conditions & 1497 & 19.7 & $36.1(11.3)$ & & $47.3(12.2)$ & \\
\hline Disease unknown & 2870 & 37.7 & $46.4(11.0)$ & & $49.9(10.8)$ & \\
\hline \multicolumn{7}{|l|}{ Overall satisfaction with care } \\
\hline High & 2713 & 36.6 & $41.6(12.3)$ & $<0.001$ & $50.4(11.3)$ & $<0.001$ \\
\hline Low & 4701 & 63.4 & 42.9 (II.5) & & 48.3 (II.0) & \\
\hline
\end{tabular}

Notes:

Unknowns were: Gender $=188$, Age $=204$, Health Status $=197$, Home ownership $=211$, Education $=260$, Employment $=212$, Marital status $=$ 200 , Country of birth $=273$ and overall satisfaction $=192$.

P-values are for comparison of component scores for categories of each characteristics using analysis of variance.

Patient characteristics were collected independently using GPAS 22 for the same respondents. 
Table 2: Scores and rotated factor loadings for items SF-I 2 scales

\begin{tabular}{|c|c|c|c|c|c|c|}
\hline \multirow[t]{2}{*}{ Scale } & \multirow[t]{2}{*}{ Desciption of items } & \multirow{2}{*}{$\begin{array}{l}\text { Lowest possible score } \\
\% \text { (No.) }\end{array}$} & \multirow{2}{*}{$\begin{array}{l}\text { Highest possible score } \\
\text { \% (No.) }\end{array}$} & \multirow{2}{*}{$\begin{array}{l}\text { Mean } \\
\text { (SD) }\end{array}$} & \multicolumn{2}{|c|}{ Factor structure } \\
\hline & & & & & Factor I & Factor 2 \\
\hline $\mathrm{PF}^{*}$ & Health limited in moderate activities & I7.I (1294) & $48.0(3638)$ & $2.31(0.74)$ & 0.85 & 0.14 \\
\hline $\mathrm{PF}^{*}$ & Health limit climbing stairs & $25.5(1916)$ & $35.8(2689)$ & $2.10(0.78)$ & 0.82 & 0.09 \\
\hline RP & Accomplished less because of physical health & $6.9(525)$ & $31.0(2352)$ & $3.57(1.25)$ & 0.84 & 0.30 \\
\hline RP & Limited in the kind of work & $7.3(551)$ & $33.3(2517)$ & $3.62(1.26)$ & 0.87 & 0.27 \\
\hline $\mathrm{BP}$ & Pain interfered with activities & $3.7(279)$ & $35.6(2701)$ & $3.74(1.21)$ & 0.71 & 0.30 \\
\hline $\mathrm{GH}$ & Health in general & $5.4(4 I I)$ & $3.0(231)$ & $3.13(1.04)$ & 0.67 & 0.33 \\
\hline $\mathrm{MH}$ & Felt calm and peaceful & $3.5(262)$ & $10.5(793)$ & $3.50(0.95)$ & 0.10 & 0.78 \\
\hline $\mathrm{MH}$ & Felt downhearted and depressed & $2.0(151)$ & $36.7(2782)$ & $3.93(1.03)$ & 0.07 & 0.83 \\
\hline RE & Accomplished less due to emotional problems & $3.7(277)$ & $45.5(3450)$ & $3.97(1.15)$ & 0.39 & 0.78 \\
\hline RE & $\begin{array}{l}\text { Did work less careful than usual due to emotional } \\
\text { problems }\end{array}$ & $3.0(228)$ & $48.8(3691)$ & $4.07(1.10)$ & 0.40 & 0.73 \\
\hline SF & $\begin{array}{l}\text { Emotional problems/physical health interfered with } \\
\text { social activities }\end{array}$ & $3.0(229)$ & $50.0(3797)$ & $4.04(1.14)$ & 0.46 & 0.68 \\
\hline VT & Lot of energy & $9.4(7 I I)$ & $4.2(3 \mid 7)$ & $3.00(1.03)$ & 0.55 & 0.49 \\
\hline
\end{tabular}

Extraction method: Principal Component Analysis. Rotation method: Varimax with Kaiser Normalization. Rotation converged in 3 iterations.

*Two items of PF are three point scale (from I to 3) and all the other items are five point scale (from I to 5).

Figures for 12 items do not include missing values which range from I. $1 \%$ to $1.6 \%$ except for the question about "climbing stars" with $2.1 \%$ missing values.

Higher loadings of each item on a factor are indicated in bold text.

regression coefficients were significant (Table 3 ) and they showed a significant improvement to the model without the interaction.

\section{Significance of parameters}

Parameter estimates were tested by the $t$ value, determined by dividing the estimated coefficients by their standard errors (Table 3) [29]. Because the two models were nested, we used -2 log likelihood, known as the "change in the deviance", which has a chi-square distribution to test whether the difference between the two models was statistically significant (Table 4).

\section{Variance explained at each level}

The baseline variance component model explained how the total variance was partitioned into variance between patients and practices (Table 4). The variance explained was estimated using the baseline model and main model [31]. Differences in the modeled variance indicate how much better a model can account for the variance at a specific level [32]. The formulas to calculate the proportion of variance explained are given by Snijders and Bosker [31] and Sixma et al. [32].

\section{Results}

There were 7606 of 12544 patient questionnaires returned (61\% return rate). We conducted analyses comparing proportions of respondents with non-respondents for gender and age (available for $90 \%$ and $84 \%$ of nonrespondents respectively). The gender of respondents (53.3\% were females) and non-respondents (53.6\% were females) were similar $(P=0.76)$. Twenty percent of nonrespondents were younger than 40 years, compared to
$10 \%$ of respondents and $14 \%$ of the total sample $(\mathrm{P}<$ $0.001)$. The mean age of respondents and non-respondents was $59.1(S D=15.0)$ and 55.3 years $(S D=17.8)$ respectively. Data completeness was excellent for all SF-12 items, with less than $1.6 \%$ of respondents not responding to each question apart from the question about "climbing stars" which $2.1 \%$ did not complete.

\section{Factor analysis}

Factor analysis suggested a two-factor solution (Table 2). These two factors account for approximately $68.1 \%$ of the variance in the twelve items of the SF-12.

Correlations between physical and mental summary scores were very low with 0.054 (principal components analysis with the varimax rotation gives uncorrelated factors). The overall mean of PCS-12 and MCS-12 of these chronically-ill respondents were $42.4(\mathrm{SD}=11.8)$ and $49.1(\mathrm{SD}=11.1)$ respectively.

Table 1 shows the characteristics of respondents and practices (independent variables). Almost one-half of the respondents were patients from large practices and $40 \%$ of respondents were from rural areas. The mean age was 60 years (range 18-96). The majority (53\%) was female and nearly $80 \%$ owned their own homes. Only $34 \%$ of respondents were employed and $40 \%$ were retired. Seventy-four per cent were born in Australia, $14 \%$ in USA, UK, Canada or New Zealand and the remaining $12 \%$ in non-English-speaking countries.

The multilevel regression included only data from the questionnaires for which information on all relevant var- 
Table 3: Estimates of regression coefficient of multilevel regression analysis for practice and patient characteristics (number of patients $=6997$; number of practices $=96$ )

\begin{tabular}{lcc}
\hline Parameters (reference category) & Estimate for the main model \\
& Physical components score (PCS-12) & Mental components score (MCS-12) \\
Regression Coefficients (Standard Error) & Regression Coefficients (Standard Error)
\end{tabular}

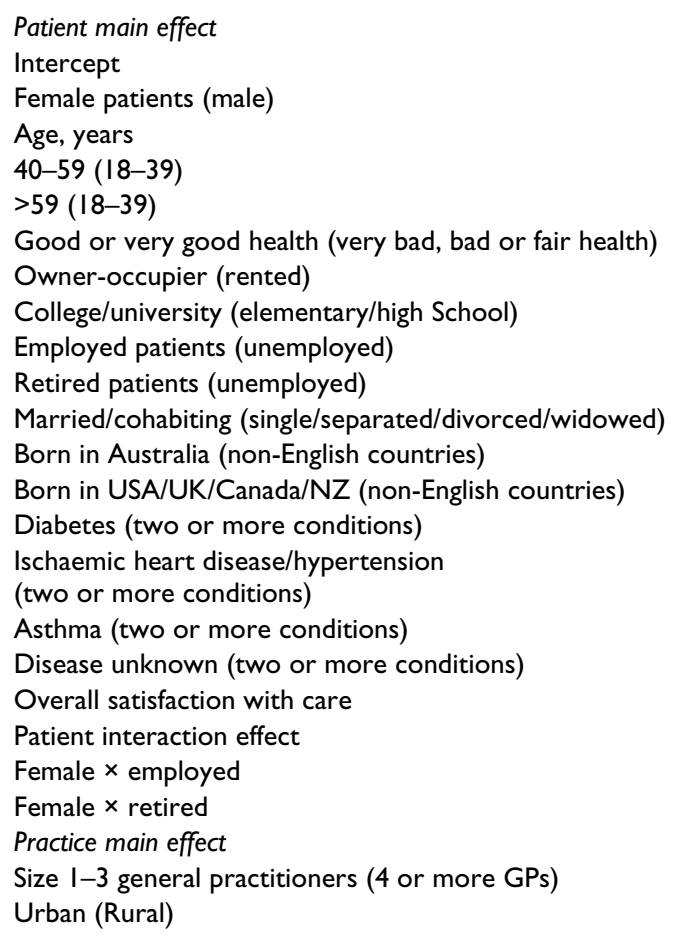

$\begin{array}{cc}35.44 & 33.74 \\ 2.78(0.46)^{\ddagger} & 1.54(0.51)^{\dagger} \\ -4.65(0.40)^{\ddagger} & 2.22(0.44)^{\ddagger} \\ -7.64(0.45)^{\ddagger} & 6.02(0.50)^{\ddagger} \\ 10.83(0.23)^{\ddagger} & 7.34(0.25)^{\ddagger} \\ 0.79(0.29)^{\dagger} & 1.72(0.32)^{\ddagger} \\ 1.02(0.25)^{\ddagger} & -0.05(0.28) \\ 7.29(0.48)^{\ddagger} & 4.81(0.52)^{\ddagger} \\ 3.99(0.48)^{\ddagger} & 3.69(0.53)^{\ddagger} \\ 0.47(0.25) & 0.63(0.27)^{*} \\ -0.68(0.35) & 1.46(0.39)^{\ddagger} \\ 0.23(0.44) & 0.87(0.48) \\ 2.66(0.37)^{\ddagger} & 1.49(0.41)^{\ddagger} \\ 1.24(0.34)^{\ddagger} & 0.55(0.37) \\ & \\ 1.01(0.42)^{*} & 1.42(0.46)^{\dagger} \\ 3.83(0.31)^{\ddagger} & 1.22(0.34)^{\ddagger} \\ -0.30(0.23) & 1.20(0.25)^{\ddagger} \\ & \\ -3.46(0.59)^{\ddagger} & -3.34(0.65)^{\ddagger} \\ -3.34(0.58)^{\ddagger} & -1.38(0.64)^{*} \\ -0.99(0.27)^{\ddagger} & \\ 0.53(0.28) & -0.55(0.26)^{*} \\ & 0.16(0.27)\end{array}$

Note: $* \mathrm{P}<0.05, \dagger \mathrm{P}<0.01, \ddagger \mathrm{P}<0.001$

Interactions not shown in the table were not included in the model.

$\mathrm{NZ}=$ New Zealand

Patient characteristics were collected independently using GPAS $^{22}$ for the same respondents.

Table 4: Estimated variances (and standard errors), percent explained variance and intra-cluster correlations for physical and mental component scores (number of patients $=6997$; number of practices $=96$ )

\begin{tabular}{|c|c|c|c|}
\hline \multirow[t]{2}{*}{ Random parameters } & \multicolumn{3}{|c|}{ Estimated variance } \\
\hline & Baseline model & Full model & \% Explained variance \\
\hline \multicolumn{4}{|l|}{ Physical component scores } \\
\hline Level 2, Practice variance & $4.40(0.92)^{\ddagger}$ & $0.60(0.25)^{*}$ & 72.9 \\
\hline Level I, Patient variance & $135.67(2.31)^{\ddagger}$ & $80.07(1.36)^{\ddagger}$ & 42.4 \\
\hline Intracluster correlation & 0.031 & 0.007 & \\
\hline Deviance & 54326.89 & 50565.05 & \\
\hline \multicolumn{4}{|l|}{ Mental component scores } \\
\hline Level 2, Practice variance & $1.32(0.43)^{\dagger}$ & $0.19(0.21)$ & 49.2 \\
\hline Level I, Patient variance & $121.59(2.07)^{\ddagger}$ & $97.0(1.65)^{\ddagger}$ & 20.9 \\
\hline Intracluster correlation & 0.011 & 0.002 & \\
\hline Deviance & 53501.64 & 51877.94 & \\
\hline
\end{tabular}

Note: $* P<0.05, \dagger P<0.01, \ddagger P<0.001$ 
iables was available, resulting in a final sample size of 6997 (92\%) patients from 96 practices. Pearson ChiSquared tests indicated that proportions of practice size, practice location, gender and country of birth were similar between the records used in multilevel analyses and missing data (data not shown). There were small but significant differences between the proportions of records analyzed and the total (including missing) for other characteristics: $0.7 \%$ (age), $0.5 \%$ (general health status), $0.3 \%$ (home ownership), $0.4 \%$ (education), $0.7 \%$ (employment), $0.3 \%$ (marital status) and $0.4 \%$ (disease).

Table 3 shows the results of the multilevel regression analyses for each of the response variables.

Patient characteristics including self-rated general health and chronic medical conditions were collected independ- ently using GPAS22 for the same respondents (Table 1). Patients' assessment of overall satisfaction with care was also assessed through the GPAS. PCS-12 declined with age, but in contrast MCS-12 increased with age. Patients with better self-reported general health status rated both PCS-12 and MCS-12 higher than those with poor general health (Table 3). Both self-reported PCS-12 and MCS-12 were positively related to home ownership. Well-educated patients tended to rate PCS-12 higher than less well-educated patients, but there was no association with MCS- 12 .

Patients who were employed or retired were likely to have higher PCS-12 and MCS-12 than unemployed. Gender interacted with employment in predicting both PCS-12 and MCS-12 with unemployment being more associated with poorer health in males than in females (Figure 1).

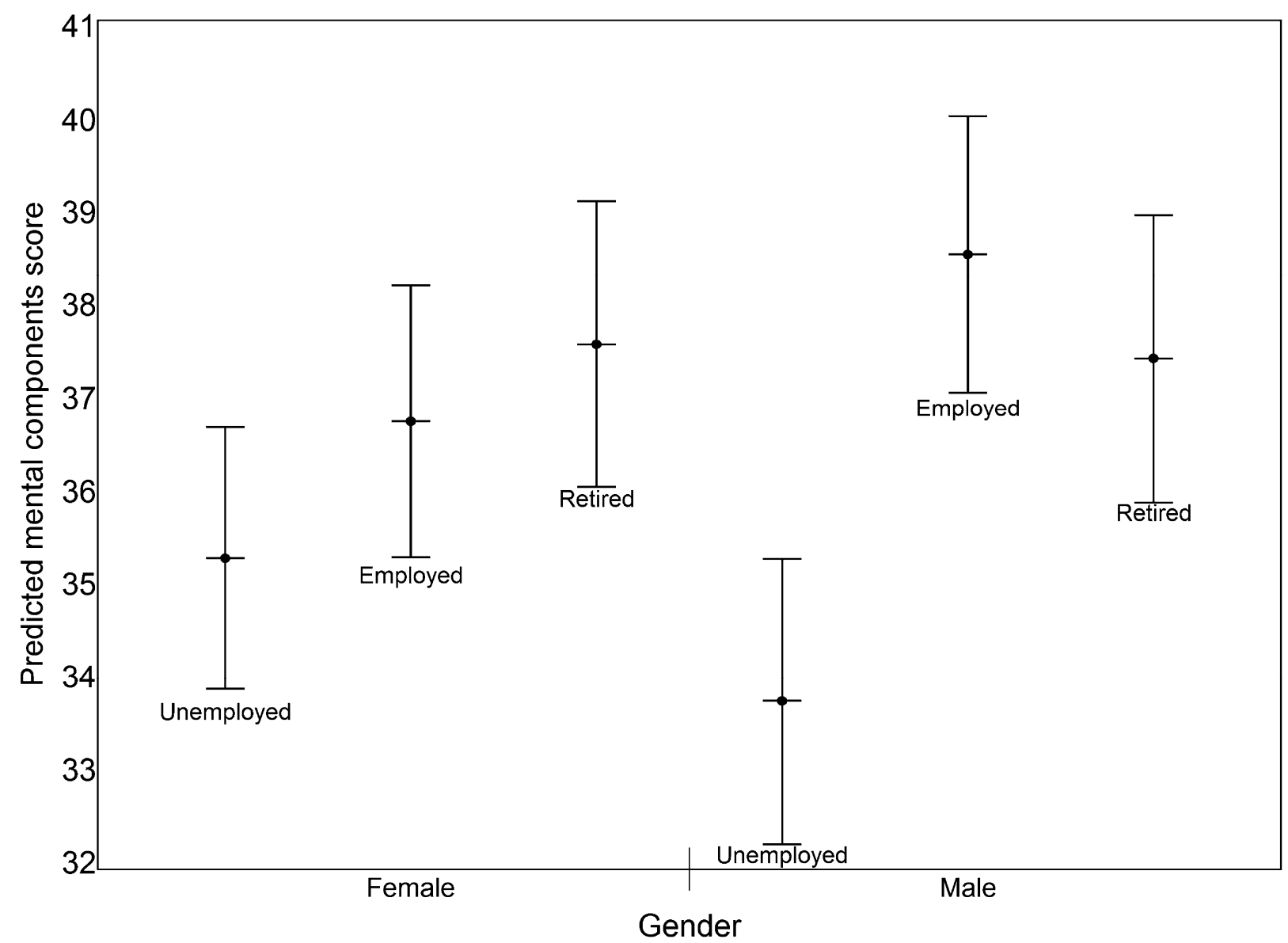

\section{Figure I}

95\% confidence intervals for predicted MCS- 12 (Mean \pm I.96 SE) by gender and employment status. Predicted values were based on the multilevel regression model with interaction between gender and employment status. 
Patients who were married or cohabiting tended to have higher MCS-12 than those who were not. Marital status did not have any effect on PCS-12. The number of chronic medical conditions was negatively associated with both MCS-12 and PCS-12. Results also showed an association between general satisfaction with care and MCS-12 but not PCS-12. Patients born in Australia were likely to have higher MCS-12 than those born in non-English-speaking countries but country of birth was not associated with PCS-12.

Patients from smaller general practices (1-3 GPs) reported lower PCS-12 and MCS-12 compared with those from larger practices. Practice location had no relationship with either PCS-12 or MCS-12.

\section{Variance components}

Ninety seven per cent of the total variance in PCS-12 was at the patient level, the remaining 3\% variance (Intra-cluster correlation $($ ICC $)=0.03$ ) was at the practice level. For MCS-12, the corresponding figures were $99 \%$ at patient level and 1\% (ICC $=0.01)$ at practice level (baseline model in Table 4). At the patient level (level 1) $42 \%$ and $21 \%$ of the variance respectively among patients for PCS12 and MCS- 12 were explained by the independent variables used in the analysis (Table 4). At the practice level (level 2), 73\% and $49 \%$ of the variance among practices for PCS-12 and MCS-12 were explained by the variables used in the analysis (Table 4).

\section{Discussion}

The SF-12 is a subjective measure of health that can be influenced by a respondent's perceptions, expectations and interpretations about health [12]. Nonetheless, the scale has become one of the most widely used HRQOL measures. This study provides the first comprehensive data on physical and mental health of chronically-ill patients in Australia.

While 103 Divisions of General Practice were approached to participate in recruiting practices to the study, only 27 Divisions agreed to participate and there were no remote area practices in the sample. Practices that volunteered to participate may not be representative of all practices within Australia or within the participating Divisions. However, the proportion of practices that were solo, or large (4 or more GPs) was similar to that reported in other studies [33]. Patients that the practice identified as being unable to read English were excluded from the study. Although the response rate of $61 \%$ was comparable with other studies [30], it is possible that some of those not responding may have had different views of their physical and mental health from those who responded. For example, $20 \%$ of non-respondents were younger than 40 years compared with $10 \%$ of respondents. These younger non- respondents would have primarily have had a diagnosis of asthma. We adjusted for these differences in distribution between the total sample (14\% from 18-39 age group) and respondents by giving greater weight to younger respondents. The results showed the mean difference between unadjusted and adjusted was 0.51 for PCS-12 (P $<0.05)$ and 0.31 for MCS-12 (P > 0.05). Finally there may have been other practice and patient factors important to patient HRQOL assessments such as patient co-payments and availability which were not specifically measured in this study and warrant further exploration in the Australian context.

It is recommended that standard US-derived scoring of the SF-12 summary scores (scores with a mean of 50 and standard deviation of 10 in the U.S. general population) can be compared and interpreted across countries [19]. For example, the average unadjusted PCS-12 (42.7) and MCS-12 (50.2) for type 2 diabetes patients were consistent with those of Canadian (PCS_12 $=42.0$ and MCS-12 $=48.5$ ) type 2 diabetes patients (Table 1 ) [34]. The overall mean of PCS-12 (42.4, SD = 11.8) and MCS-12 (49.1, SD $=11.1$ ) of chronically-ill patients in the study were less than those of U.S. general population (mean $=50, \mathrm{SD}=$ $10)$. The difference for PCS-12 was clinically significant with effect size of 0.69 and that for MCS-12 was not clinically significant (effect size $=0.09$ ). The effect size of more than 0.5 is considered to be clinically significant [8]. The difference between the PCS-12 in this study and that of the Australian general population (PCS- $12=50.9, \mathrm{SD}=$ 8.7) [35] was clinically significant (effect size $=0.82$ ). However, the difference between the MCS-12 and that of the general population (MCS-12 $=50.3, \mathrm{SD}=9.9$ ) was clinically not significant (effect size $=0.11$ ) [35].

We also examined ceiling (highest possible score) or floor effects (lowest possible score) of 12 items and their loadings on each factor. All floor effects were $<15 \%$ except for two PF items with the limited answering options (both items are on a 3-point scale) but ceiling effects for some items (item/items of PF, RP, BP, RE and SF) were $>15 \%$. Such ceiling effects are seen in both the SF-36 [36] and SF12 [37]. Large ceiling effects are undesirable because they reduce scale sensitivity [36]. Ceiling or floor effects were less than $0.04 \%$ for both PCS- 12 and MCS- 12 . VT and SF were the most confounded in PCS-12 and MCS-12 (Table 2). Principal component scores offer a solution to this confounding.

The practice level variance for PCS-12 was small but significant even after adjustment for patient and practice characteristics which supports the choice of multilevel analysis. That of MCS-12 was not significant after adjustment. The large patient level variance is consistent with other studies $[14,30]$. This suggests that most of the differ- 
ences between patients may be related to patient selection rather than differences in the care provided by practices. There was a negative effect of size of practice on both PCS12 and MCS-12 that may reflect the decreased continuity of care provided in larger practices and patients with poor health may have self-selected smaller practices for better continuity of care [38]. Most of the variance in both PCS12 and MCS-12 was related to patient level factors such as age, socio-economic status and ethnicity. Socio-economic status was measured by employment, home ownership and education. The effects of home ownership and education were clinically not significant (effect size $<0.5$ ), but the effect of employment was clinically significant for PCS-12. Further studies of this type are required to identify other variables that explain the variance in MCS- 12 . By contrast practice size and other independent variables explained most of the practice level variance in both PCS12 and MCS-12.

Our finding that PCS-12 was lower in older age while MCS-12 was higher in older age groups is consistent with previous research $[7,9,11,14,18,39]$. In clinical practice this underlines the importance of looking for psychological distress in association with chronic illnesses such as hypertension/ischaemic heart disease, diabetes and asthma, and in younger age groups and unemployed.

Consistent with other research, lower socio-economic groups reported lower PCS-12 and MCS-12 [7,11,14]. Our previous research indicated that while Australian general practitioners working in low income areas provided fewer long consultations, other markers of process of care for diabetes were better $[40,41]$. Thus while the socio-economic gap in HRQOL may not be attributable to differences in quality of general practice care, it does suggest that greater effort is needed to improve outcomes for low socio-economic chronically-ill patients and that GPs working with these patients may require additional support such as practice nurses or allied health providers.

People from non-English-speaking backgrounds had lower MCS-12 but not PCS-12. Again this is consistent with other research $[7,9]$. We do not have information on the circumstances of patient migration (especially the proportion who were refugees), however it is possible that the worse mental health may have been due to acculturation issues. Patients from non-English-speaking backgrounds were also less satisfied with their care [38].

Some studies have shown a significant interaction effect between gender and employment indicating employed men enjoy higher levels of general well-being $[15,28]$. In this study there was an interaction between gender and employment status with the negative impact of unemployment being greater in male than female patients.
Male employed respondents were likely to have higher physical and mental health than unemployed males (large effect sizes of 1.37 and 0.70 for PCS-12 and MCS12 respectively). The effect of employment was less on females. This may be because the significance of work and its impact on household income may be greater in chronically-ill older men than in women [27]. The 'unemployed' category in our study included people who were unable to work due to sickness or disability ( $11 \%$ of males and $7 \%$ of females) and looking after family or home (1\% of males and $19 \%$ of females). Probably, this might explain some of the interaction.

\section{Policy and practice implications}

Based on the results of the analysis reported here, the SF12 and its component scales appear to be valid and useful tools to use in identifying differences in quality of life of the chronically-ill Australian population on the basis of social determinants of health [7]. Known group comparisons based upon differences in general health, age, socioeconomic status, and number of medical conditions yielded support for the construct validity of the SF-12 in this data $[8,10,42]$. Further, our data showed an association between general satisfaction with care or marital status with mental health but not with physical health confirming the results of previous studies [43-45]. In our sample it appeared that the dimensions were discriminative enough to distinguish between respondents with a single illness and with two or more illnesses or low and high socio-economic status or younger and older respondents. Further, there was strong association between SF-12 summary scores and self-rated general health status collected independently using GPAS for the same respondents (clinically significant large effect sizes of 1.27 and 0.79 for PCS-12 and MCS-12 respectively). This ability to discriminate between groups means that clinicians can use scores better to understand the functional status and health care needs of at-risk subgroups, and also enables policy makers to measure clinical effectiveness [10]. The ability to detect previously hypothesized differences or associations between variables showed the construct validity of SF-12 in Australia [6]. Further, the results suggest that the SF-12 has construct validity when applied to an Australian primary care population with chronic illness.

\section{Conclusion}

The strong association between patient characteristics such as socio-economic status, age, and ethnicity and SF12 physical and mental component summary scores underlines the importance of considering these factors in the management of chronically-ill patients in general practice and adjusting for them in the assessment of the performance of practices. The SF-12 appears to be a valid 
measure for assessing HRQOL of Australian chronicallyill patients.

\section{List of abbreviations}

BP: Bodily Pain; GH: General Health; GP: General Practitioner; GPAS: General Practice Assessment Survey; HRQOL: Health-Related Quality of Life; ICC: Intra-Cluster Correlation; MCS: Mental Health Component Summary; MCS-12: Mental Component Score derived from the SF-12; MH: Mental Health; PCS: Physical Component Summary; PCS-12: Physical Component Score derived from the SF-12; PCS-36: Physical Component Score derived from the SF-36; PF: Physical Functioning; RE: Role Emotional; RP: Role Physical; RRMA: Rural, Remote and Metropolitan Area; SD: Standard Deviation; SF: Social Functioning; SF-12: Short Form 12-item Health Survey; SF-36: Short Form 36-item Health Survey; VT: Vitality.

\section{Competing interests}

The authors declare that they have no competing interests.

\section{Authors' contributions}

UJ contributed to data analysis, interpreting the data and drafting the manuscript. UJ and MH made substantial contributions to conception and design of the study. JP, $\mathrm{CA}, \mathrm{CH}$ were involved in the data collection. All authors were involved in drafting the manuscript or revising it critically for important intellectual content. All authors have read and approved the final version of the manuscript.

\section{Acknowledgements}

This study was funded by the Australian Department of Health and Ageing. The Department of Health and Ageing was not involved in the study design, data collection, analysis or interpretation, and had no influence on the writing and submission of this article. The investigators would like to thank the participating patients, and general practices and their staff, and the participating Divisions of General Practice for their assistance in recruiting practices and assisting practices with the feedback provided to them. We would also like to thank other members of the PRACCAP study group, Jane Grimm, Edward Swan, and Tanya Bubner for their valuable contribution and Dr. Sarah Dennis for her comments. Our thanks also go to Sheryl Scharkie, Roy Batterham, Heidi DePaoli and Robyn Alexander for their assistance with data collection. JP is grateful to the National Health and Medical Research Council (Program Grant 510135) for salary support.

\section{References}

I. Australian Institute of Health and Welfare: Chronic disease and associated risk factors in Australia. 2006 [http:// www.aihw.gov.au/publications/phe/cdarfa06/cdarfa06.pdf]. Canberra: AlHW

2. Australian Institute of Health and Welfare: Chronic diseases and associated risk factors in Australia. Canberra: AlHW; $200 \mathrm{I}$.

3. Britt H, Miller G, Knox S, Charles J, Valenti L, Pan Y, Henderson J, Bayram C, O'Halloran J, Ng A: General Practice Activity in Australia 2003-4. 2004 [http://www.aihw.gov.au/publications/gep/ gpaa03-04/gpaa03-04.pdf]. Canberra: Australian Institute of Health and Welfare

4. Commonwealth Department of Health and Aged Care $(\mathrm{CDoHaA})$ Enhanced primary care program. 2007 [http:// www.health.gov.au/internet/main/publishing.nsf/Content/ Enhanced+Primary+Care+Program-I].
5. Harris MF, Zwar N: Care of patients with chronic disease: the challenge for general practice. MJA 2007, I 87: I04-107.

6. Jenkinson C, Chandola T, Coulter A, Bruster S: An assessment of the construct validity of the SF-I 2 summary scores ethnic groups. J Public Health Med 2001, 23:187-194.

7. Burdine JN, Felix MRJ, Abel AL, Wiltraut CJ, Musselman YJ: The SFI 2 as a Population Health Measure: An Exploratory Examination of Potential for Application. Health Serv Res 2000, 35:885-904.

8. Lim LLY, Fisher JD: Use of the I2-item Short-Form (SF-12) Health Survey in an Australian heart and stroke population. Qual Life Res 1999, 8:1-8.

9. Fleishman JA, Lawarence WF: Demographic Variation in SF-I 2 Scores: True Differences or Differential Item Functioning. Med Care 2003, 4 I (Suppl 7):III-75-III-86.

10. Lubetkin El, Jia H, Gold MR: Use of the SF-36 in Low-Income Chinese American Primary Care Patients. Med Care 2003 41:447-457.

II. Fone D, Dunstan F, Lloyd K, Williams G, Watkins J, Palmer S: Does social cohesion modify the association between area income deprivation and mental health? A multilevel analysis. Int J Epidemiol 2007, 36:338-345.

12. Keles H, Ekici A, Ekici M, Bulcun E, Altinkaya V: Effect of chronic diseases and associated psychological distress on heathrelated quality of life. Internal Medicne Journal 2007, 37:6- II.

13. Ferrer RL, Palmer R: Variation in health status within and between socioeconomic strata. I Epidemiol Community Health 2004, 58:38I-387.

14. Wainwright NW], Surtees PG: Places, people, and their physical and mental functional health. J Epidemiol Community Health 2003, 58:333-339.

I5. Lennon MC: Sex Differences in Distress: The Impact of Gender and Work Roles. J Health Soc Behav 1987, 28:290-305.

16. Hodacre AL, Keane M, Kaulcy E, Moretti C: Making the connections. In Report of the 2004-2005 Annual Survey of Divisions of General Practice Adelaide: Primary Health Care Research \& Information Service; 2006

17. Ware JEJ, Kosinski M, Turner-Bowker DM, Gandek B: How to Score Version 2 of the SF-1 2 Health Survey (With a supplement Documenting Version I). Lincoln, RI: QualityMetric Incorporated; 2002.

18. Schofield MJ, Mishra G: Validity of the SF-I 2 Compared with the SF-36 Health Survey in Pilot Studies of the Australian Longitudinal Study on Women's Health. Journal of Health Psychology 1998, 3:259-271.

19. Gandek B, Ware JE, Aaronson NK, Apolone G, Bjorner JB, Brazier JE, Bullinger M, Kaasa S, Leplege A, Prieto L, Sullivan M: Cross-Validation of Item Selection and Scoring for the SF- I 2 Health Survey in Nine Countries: Results from the IQOLA Project. J Clin Epidemiol 1998, 51:1171-1178.

20. Sanderson K, Andrews G: The SF-I 2 in the Australian population: cross-validation of item selection. Aust N Z J Public Health 2002, 26:343-345.

21. Wilson D, Tucker G, Chittleborough C: Rethinking and rescoring the SF-I 2. Soz Praventivmed. 2002, 47(3): I72-I77.

22. National Primary Care Research and Development Centre: Manual: General Practice Assessment Survey (GPAS) Version 2. Manchester: University of Manchester; 200I.

23. Bower $P$, Mead $N$, Roland $M$ : What dimensions underlie patient responses to the General Practice Assessment Survey? A factor analytic study. Fam Pract 2002, 19:489-495.

24. Australian Department of Primary Industries and Energy: Rural, Remote and Metropolitan Areas (RRMA) Classification. Canberra: DPIE; 1994.

25. Macintyre S, Ellaway A, Der G, Ford G, Hunt K: Do housing tenure and car access predict health because they are simply markers of income of self esteem? A Scottish study. J Epidemiol Community Health 1998, 52:657-664.

26. Kontodimopoulos N, Pappa E, Niakas D, Tountas Y: Validity of SFI 2 summary scores in a Greek general population. Health Qual Life Outcomes. 2007, 5:55.

27. Stolzenberg RM: It's about Time and Gender: Spousal Employment and Heath. A/S 200I, I07:61-100

28. Artazcoz L, Benach J, Borrell C, Cortes I: Unemployment and Mental Health: Understanding the Interactions Among Gen- 
der, Family Roles, and Social Class. Am J Public Health 2004, 94:82-88.

29. Rasbash J, Steele F, Browne W, Prosser B: A user's guide to MLwiN version 2.0. In Centre for multilevel modelling Bristol: University of Bristol; 2005.

30. Fone DL, Lloyd K, Dunstan FD: Measuring the neighbourhood using UK benefits data: a multilevel analysis of mental heath status. BMC Public Health 2007, 7:69.

31. Snijders TAB, Bosker RJ: Multilevel Analysis: An introduction to basic and advanced multilevel modeling London: Sage Publications; 1999.

32. Sixma HJ, Spreenwenberg PM, Pasch MA Van der: Patient satisfaction with the general practitioner: a two-level analysis. Med Care 1998, 36:212-229.

33. Commonwealth Department of Health and Aged Care: General Practice in Australia Canberra: DoHA; 2000.

34. Johnson JA, Maddigan SL: Performance of the RAND- 12 and SF12 summary scores in type 2 diabetes. Qual Life Res 2004 13:449-456.

35. Windsor TD, Rodgers B, Butterworth P, Anstey KJ, Jorm AF: Measuring physical and mental health using the SF-12: implications for community surveys of mental health. Aust $N Z J$ Psychiatry 2006, 40:797-803.

36. Wyrwich KW, Nienaber NA, Tierney WM, Wolinsky FD: Linking Clinical Relevance and Statistical Significance in Evaluating Intra - Individual Changes in Health - Related Quality of Life. Med Care 1999, 37:469-478.

37. Larson CO, Schlundt D, Patel K, Beard K, Hargreaves M: Validity of the SF- 12 for use in a low-income African American community-based research initiative (REACH 2010). Prev Chronic Dis 2008, 5(2):A44.

38. Jayasinghe UW, Proudfoot J, Holton C, Powell Davies G, Amoroso C Bubner T, Beilby J, Harris MF: Chronically ill Australians' satisfaction with accessibility and patient-centredness. Int J Qual Health Care 2008, 20: 105-114.

39. Mishra G, Schofield MJ: Norms for the physical and mental health component summary scores of the SF-36 for young, middle aged and older Australian women. Qual Life Res 1998, 7:215-220.

40. Furler JS, Harris E, Chondros P, Powell Davies PG, Harris MF, Young $D Y L$ : The inverse care law revisited: impact of disadvantaged location on accessing longer GP consultation times. Med J Aust 2002, 177:80-83.

41. Georgiou A, Burns J, Harris MF: GP Claims for completing diabetes 'cycle of care'. Aust Fam Physician 2004, 33:755-757.

42. Alexander M, Berger W, Buchhloz P, Walt J, Burk C, Lee J, Arbuckle $R$, Abetz $L$ : The reliability, validity, and preliminary representatives of the Eye Allergy Patient Impact Questionnaire (EAPIQ). Health and Quality of Life Outcomes 2005, 3:67.

43. Marshall GN, Hays RD, Rand RM: Health status and satisfaction with health care: Results from the Medical Outcome Study. J Consult Clin Psychol 1996, 64:380-390.

44. Johnson JA, Coons SJ, Hays RD, Pickard AS: Health status and satisfaction with pharmacy services. Am J Manag Care. 1999, 5(2): $163-170$

45. Sherbourne $C D$, Hays RD: Marital status, social support, and health transitions in chronic disease patients. J Health Soc Behav 1990, 31 : 328-343.
Publish with Bio Med Central and every scientist can read your work free of charge

"BioMed Central will be the most significant development for disseminating the results of biomedical research in our lifetime. "

Sir Paul Nurse, Cancer Research UK

Your research papers will be:

- available free of charge to the entire biomedical community

- peer reviewed and published immediately upon acceptance

- cited in PubMed and archived on PubMed Central

- yours - you keep the copyright
BioMedcentral 